\title{
86834 - MORTE, PERCEPÇÃO DE ENVELHECIMENTO E EDUCAÇÃO EM SAÚDE: A PERCEPÇÃO EM FINITUDE DA VIDA POR PROFISSIONAIS E ESTUDANTES DE SAÚDE - UM RELATO DE EXPERIÊNCIA
}

\section{Pôster - Gerontologia}

Jeovana Ceresa / CERESA, J. / acadêmica do curso de Medicina, Universidade Federal do Rio Grande do Sul (UFRGS);

Guilherme Silva Costa / COSTA, G. S. / Acadêmico do Curso de Biomedicina, Universidade Federal de Ciências da Saúde de Porto Alegre; Guilherme Briczinski / BRICZINSKI, G. / acadêmico do curso de Fonoaudiologia, Universidade Federal de Ciências da Saúde de Porto Alegre; Juliane Pinto Lucero / LUCERO, J. P. / ) acadêmica do curso de Enfermagem, Universidade Federal de Ciências da Saúde de Porto Alegre;

Eduardo Garcia / GARCIA, E. / professor orientador da Liga de Geriatria e Gerontologia da Universidade Federal de Ciências da Saúde de Porto Alegre e docente da mesma instituição, Universidade Federal de

Ciências da Saúde de Porto Alegre (UFCSPA)

Introdução. Dados os avanços em relação às propedêuticas e terapêuticas em saúde, uma prática clínica que proporcionasse também avanços e incrementos substanciais em qualidade de vida dos pacientes e tratamento seria condizente. Muitas vezes, impõe-se a pacientes idosos terapias que postergam sua existência negligenciando as consequências do viver e efeitos adversos: a vida é priorizada, independendo da qualidade da existência e tal pensamento culminou em um distanciamento da morte, representada pelo fracasso terapêutico e profissional e afastamento do paciente e de discussões sobre o processo de finitude da vida. Contudo, os objetivos terapêuticos nem sempre são atingidos e, inevitavelmente, tópicos como morte e sofrimento no envelhecimento não são devidamente discutidos na formação dos profissionais da saúde. Objetivo. Apresentar os resultados relacionados com a percepção da morte e processo de envelhecimento em profissionais da saúde presentes em evento acerca do tópico em Porto Alegre. Metodologia. Aplicação de questionário objetivo formado com 8 questões a profissionais e acadêmicos da área da saúde em 2018. Resultados. 110 participantes (acadêmicos ou profissionais da área da saúde), sendo $91 \%$ do sexo feminino e na faixa etária de 19 a 69 anos. A definição de morte foi a de representação de um processo natural de envelhecimento para 45\%, 23\% nunca pensou acerca da própria morte, 44,5\% já vivenciou uma experiência citada como traumática no processo de envelhecer ou morrer; somente $12,7 \%$ acredita que ao longo da formação acadêmica e profissional teve preparo teórico e prático para o tópico; 91,8\% discorda que a morte é um tema a ser evitado; $40 \%$ concorda em algum grau que seja fundamental a profissionais da saúde tenham alguma crença espiritual para tratar de situações de morte ou envelhecimento e 79,1\% discorda de que o paciente ter conhecimento acerca da gravidade de sua doença contribui para a piora do estado. Conclusões: Urge que se discuta sobre 
morte e envelhecimento no âmbito da formação de profissionais da saúde: 83,7\% dos participantes acreditam não possuir o embasamento teórico, prático e psicológico adequado para o manejo de tais situações - assim, é necessário maior enfoque no tema na educação em saúde, com o intuito de preparar psicologicamente futuros profissionais ante a terminalidade da vida e envelhecimento, a fim de gerar um desempenho profissional e pessoal mais saudável.

Palavras-chave: Liga Acadêmica, Geriatria, Gerontologia. 